\title{
Lignosulfonic Acid-Induced Inhibition of Intestinal Glucose Absorption
}

\author{
Yasushi Hasegawa, Yukiya Kadota, Chihiro HaSegaWA and Satoshi KaWAminami \\ College of Environmental Technology, Muroran Institute of Technology, 27-1 Mizumoto, \\ Muroran 050-8585, Japan \\ (Received April 27, 2015)
}

\begin{abstract}
Summary Lignosulfonic acid is a waste lignin produced from the sulfite pulping of softwood. We investigated the effect of lignosulfonic acid on $\alpha$-glucosidase and found that lignosulfonic acid produced a reversible and non-competitive inhibition of the enzyme activity. Moreover, in human colorectal adenocarcinoma cells, lignosulfonic acid inhibited 2-deoxyglucose uptake, while in vivo studies demonstrated a significant reduction in the blood glycemic response to sucrose or glucose ingestion in rats treated with lignosulfonic acid. Feces of rats fed a diet supplemented with 5\% lignosulfonic acid had higher sugar content compared to those of rats fed a control diet. These results suggest that lignosulfonic acid suppresses the rise in blood glucose levels through inhibition of $\alpha$-glucosidase activity and intestinal glucose absorption.
\end{abstract}

Key Words blood glucose, glucose absorption, $\alpha$-glucosidase, lignosulfonic acid

Lignins are natural polymers derived from wood. They are formed by a random combination of three aromatic alcohols: coniferyl alcohol, p-coumaryl alcohol, and sinapyl alcohol. Lignosulfonic acid is a waste byproduct derived from the sulfite pulping of softwood that is used in paper industry. Being a water-soluble polydisperse polyelectrolyte (1), lignosulfonic acid has a variety of industrial applications. Thus, lignosulfonic acid has been used in the proton-conductive membranes of direct-methanol fuel cells (2), as a plasticizer in the production of concrete (3) and as a raw material in the production of artificial vanilla flavor, vanillin (4). Given the non-toxic and versatile nature of the compound, further utilization of lignosulfonic acid can undoubtedly be achieved.

Lignins are non-toxic compounds present in a large variety of foods and cereal brands. They are the major components of insoluble dietary fiber that is resistant to digestion by human intestinal enzymes. Although dietary fiber has been shown to be effective in the prevention of many diseases, including colon cancer, heart disease, obesity, and diabetes, little attention has been paid to the biological activities of lignin because of the difficulty of isolation. However, there are some studies that show that lignins are involved in a number of biological activities. For example, they reduce serum cholesterol by binding to the bile acids in the intestine $(5,6)$ and, due to the presence of the multi-functional phenolic polymers, act as free radical scavengers and antioxidants $(7,8)$. Reddy et al. (9) showed that in rats exposed to an intestinal carcinogen 3,2-dimetyl-4-aminobiphenyl, a lignin diet led to reduction in the small intestine tumor development. Moreover, soluble lignins and lignosulfonic acid have been reported to possess

E-mail: hasegawa@mmm.muroran-it.ac.jp antiviral and immunopotentiating properties (10, 11). The biological activities listed above make lignins and lignin-derivatives particularly attractive for cosmetic, pharmaceutical and food processing industries.

Postprandial hyperglycemia plays an important role in the development of type 2 diabetes. Therapeutic approaches for managing postprandial hyperglycemia are directed at retardation of intestinal glucose absorption through inhibition of the carbohydrate hydrolyzing enzymes (e.g., $\alpha$-amylase and $\alpha$-glucosidase) and at suppression of the intestinal glucose uptake by glucose transporters. Many studies have been conducted in an attempt to find natural products that inhibit $\alpha$-amylase and $\alpha$-glucosidase activities and intestinal glucose transport. However, effects of lignin against postprandial hyperglycemia have not been reported.

The main goal of our study was to find novel applications for the lignin derivative, lignosulfonic acid. In pursuance of this goal, we investigated the effects of lignosulfonic acid on $\alpha$-glucosidase activity and 2-deoxyglucose uptake in human colorectal carcinoma cells, and on the intestinal glucose absorption in a rat animal model.

\section{MATERIALS AND METHODS}

Reagents. Low (approximately $8 \mathrm{kDa}$ ) molecular weight lignosulfonic acid and $p$-nitrophenyl $\alpha$-D-glucoside (PNP-Gluc) were purchased from Sigma-Aldrich (St. Louis, MO). Yeast $\alpha$-glucosidase was purchased from Wako Pure Chemical Industries, Ltd. (Osaka, Japan). Human colorectal adenocarcinoma, Caco-2, cells were obtained from Riken Bioresource Center (Tsukuba, Japan).

Alpha glucosidase inhibition assay. The activity of $\alpha$-glycosidase was measured according to the protocol described in Lee and Lee (12). Briefly, lignosulfonic 
acid, at various concentrations, was added to $0.2 \mathrm{U} / \mathrm{mL}$ of $\alpha$-glucosidase in $50 \mathrm{~mm}$ phosphate buffer ( $\mathrm{pH} 7.0$ ) and incubated for $30 \mathrm{~min}$ at $25^{\circ} \mathrm{C}$. After that, PNPGluc solution was added to reach $10 \mathrm{~mm}$ for initiating an enzymatic reaction. The reaction was carried out at $25^{\circ} \mathrm{C}$, and three volumes of $1 \mathrm{M} \mathrm{Na}_{2} \mathrm{CO}_{3}$ were then added to terminate the reaction. Enzymatic activity was measured at the absorbance wavelength of $405 \mathrm{~nm}$. In order to determine the mode of $\alpha$-glucosidase inhibition by lignosulfonic acid, enzymatic activity was measured with increasing concentrations of PNP-Gluc in the absence or presence of different concentrations of lignosulfonic acid.

In addition, $\alpha$-glucosidase (approximately $68 \mathrm{kDa}$ molecular weight) was incubated with $20 \mu \mathrm{M}$ of lignosulfonic acid in $50 \mathrm{~mm}$ phosphate buffer ( $\mathrm{pH} 7.0$ ) for $2 \mathrm{~h}$ at $25^{\circ} \mathrm{C}$ and one half of the solution was used for enzyme activity. The other half was fractionated by the Amicon Ultra Centrifugal Filter Device with $10 \mathrm{kDa}$ molecular weight exclusion limit (Millipore, Billerica, MA) and the concentrated fraction on the filter was diluted with $50 \mathrm{~mm}$ phosphate buffer $(\mathrm{pH} 7.0)$ and used for enzyme activity. To determine whether the binding of $\alpha$-glucosidase to lignosulfonic acid was reversible, the activities of $\alpha$-glucosidase were compared before and after fractionation.

Human colorectal adenocarcinoma, Caco-2, cells culture and 2-deoxyglucose uptake assay. Caco-2 cells were maintained in $5 \% \mathrm{CO}_{2}$ at $37^{\circ} \mathrm{C}$ in Eagle's minimum essential medium supplemented with $20 \%$ fetal calf serum. For 2-deoxyglucose uptake assay, the cells were seeded at $6 \times 10^{4}$ cells per well in a 6 -well culture plate. When cells reached approximately $80 \%$ confluence, the regular growth medium was replaced by the serum-free medium and the cells were returned to the incubator. Six hours later, the cells were washed three times with KrebsRinger phosphate buffer (KRP buffer containing 136 $\mathrm{mM} \mathrm{NaCl}, 5 \mathrm{mM} \mathrm{Na}_{2} \mathrm{HPO}_{4}, 4.7 \mathrm{mM} \mathrm{KCl}, 1 \mathrm{mM} \mathrm{MgSO}$, $20 \mathrm{~mm}$ HEPES-NaOH (pH 7.0) and $1 \mathrm{mM} \mathrm{CaCl}_{2}$ ), and then incubated in KRP buffer containing 2\% bovine serum albumin for $20 \mathrm{~min}$ at $37^{\circ} \mathrm{C}$. Various concentrations of lignosulfonic acid and $1 \mathrm{~mm}$ of 2-deoxyglucose were added and the cells were incubated for $20 \mathrm{~min}$ at $37^{\circ} \mathrm{C}$. After being removed from the solution, cells were washed three times with PBS and then resuspended in $10 \mathrm{mM}$ Tris-HCl ( $\mathrm{pH} 7.5)$. After sonication and heat treatment for $15 \mathrm{~min}$ at $95^{\circ} \mathrm{C}$, homogenized cells were pelleted by centrifugation at $14,000 \times g$ for $15 \mathrm{~min}$ and the supernatant was recovered. The amount of 2-deoxyglucose in the supernatant was measured using a 2-deoxyglucose uptake measurement kit (Cosmo Bio, Tokyo, Japan).

Cell viability. Viability of 3T3-L1 cells was determined using the (3-(4,5-dimethylthiazol-2-yl)-2,5-diphenyltetrazolium bromide (MTT) assay (13). Caco-2 cells were seeded at $1 \times 10^{4}$ cells per well in a 24-well culture plate and lignosulfonic acid was added at concentrations of $62.5 \mu \mathrm{M}$ or $125 \mu \mathrm{M}$. After $24 \mathrm{~h}$, MTT $(0.5 \mathrm{mg} / \mathrm{mL})$ was added to each well and the cells were incubated for $4 \mathrm{~h}$ at $37^{\circ} \mathrm{C}$. The medium was then carefully aspirated, and $200 \mu \mathrm{L}$ of $20 \%$ sodium dodecyl sul- fate (SDS) was added to solubilize the colored product. After $24 \mathrm{~h}$, the absorbance was measured at $570 \mathrm{~nm}$.

Measurement of glucose diffusion. The effect of lignosulfonic acid on glucose diffusion was measured according to a slight modification of the method of $\mathrm{Ou}$ et al. (14). Briefly, $100 \mathrm{~mm}$ glucose in the absence or presence of lignosulfonic acid was placed in a dialysis tube and then dialyzed against $500 \mathrm{~mL}$ deionized water at room temperature. The glucose content in the dialysis tube at the indicated time was determined using a glucose measuring kit (Wako).

Measurements of the effect of lignosulfonic acid on blood glucose levels after sucrose or glucose loading. Six-weekold Wistar rats were purchased from CLEA Japan, Inc. (Tokyo, Japan) and allowed free access to a commercial diet (Oriental Yeast Co., Ltd., Tokyo, Japan) for $7 \mathrm{~d}$ before the start of the experiment. After 24-h food deprivation, either sucrose $(1.5 \mathrm{~g} / \mathrm{kg})$ or glucose $(1.5 \mathrm{~g} / \mathrm{kg})$ was administered orally simultaneously with lignosulfonic acid $(50$ or $100 \mathrm{mg} / \mathrm{kg}$ ). The rats of the control group were given sucrose or glucose only. There were four rats in each group. Blood samples were taken from the tail vein before sucrose or glucose administration, and at 30-, 60-, and 120-min intervals post administration. Blood glucose concentration was measured using a glucometer and test-strips (Abbott, North Chicago, IL). The average of three measurements at each time point for each rat was calculated and used for statistical analysis.

Animals and diet. Four-week-old male Wistar rats were housed individually and allowed to acclimate for a week post arrival in a room maintained at $25^{\circ} \mathrm{C}$. The animals were provided with water ad libitum. The rats were cared for in accordance with the Guidelines for Experimental Animal Care issued by the Office of the Prime Minister of Japan. After the acclimatization period, the rats were randomly divided into two groups (of 5 animals each) and fed for $4 \mathrm{wk}$ with either a high-fat diet (control diet) or a high-fat diet supplemented with 5\% lignosulfonic acid (lignosulfonic acid diet). The basal high-fat diet consisted of (in wt.\%) casein, 20; cornstarch, 15; corn oil, 5; AIN-76 mineral mixture, 5; AIN76A vitamin mixture, 1.0; L-cystein, 0.3; choline, 0.2; lard, 20; sucrose, 27; and cellulose, 3. For the group fed the lignosulfonic acid diet or control diet, 5 wt. $\%$ of lignosulfonic acid or cellulose was added to the basal highfat diet, respectively. The rats received $10 \mathrm{~g}$ of food daily and had free access to water. The amount of leftover food was monitored daily. Body weights were measured every week. After feces were collected every week, and dried under vacuum, fecal weight per week was determined. To determine sugar content, feces were ground to a powder and sugars were extracted with deionized water. Sugar content was measured by the phenol sulfite method.

Statistical analysis. Each experiment was performed at least three times. Data were expressed as the mean and the standard error of mean (SE). Data were analyzed by one-way analysis of variance (one-way ANOVA) followed by Turkey's multiple-comparison test or Student's t-test. 


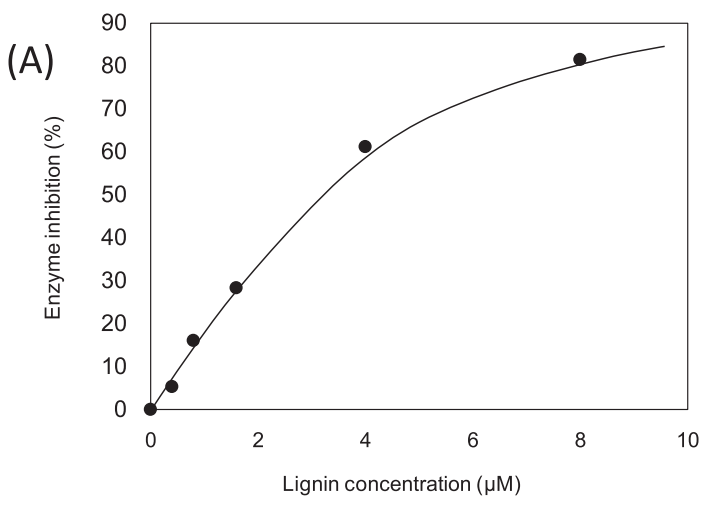

(B)
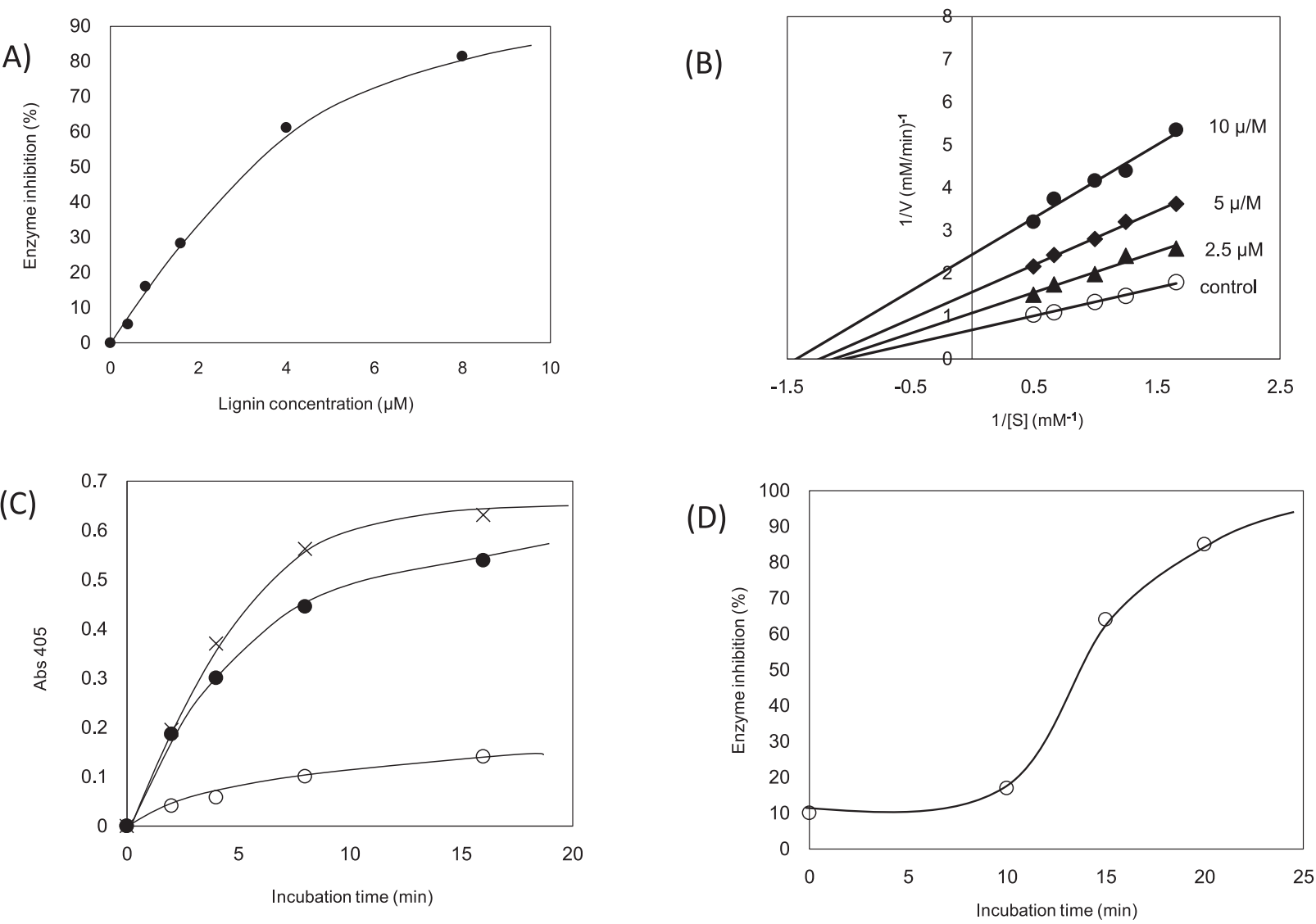

Fig. 1. Effect of lignosulfonic acid on $\alpha$-glucosidase activity. (A) Inhibition of $\alpha$-glucosidase activity by the indicated concentrations of lignosulfonic acid. (B) Double-reciprocal plots of the inhibition kinetics of $\alpha$-glucosidase by lignosulfonic acid. Alpha-glucosidase activity was measured with indicated concentrations of PNP glucoside in the absence or presence of various concentrations of lignosulfonic acid. (C) Reversible inhibition of $\alpha$-glucosidase activity by lignosulfonic acid. After $\alpha$-glucosidase $(0.2 \mathrm{U} / \mathrm{mL})$ was incubated with $20 \mu \mathrm{M}$ of lignosulfonic acid, one half of the solution was used for enzyme activity $(\bigcirc)$. The other was fractionated by the Amicon Ultra Centrifugal Filter Device and the concentrated fraction on the filter was used for enzyme activity $(-)$. The activity of $\alpha$-glucosidase $(0.2 \mathrm{U} / \mathrm{mL})$ in the absence of lignosulfonic acid was also measured $(\times)$. Absorbance of generated PNP was plotted against the reaction time. (D) Incubation timedependent inhibition of $\alpha$-glucosidase activity by lignosulfonic acid.

\section{RESULTS}

Inhibition of $\alpha$-glucosidase activity by lignosulfonic acid

We found that lignosulfonic acid inhibited $\alpha$-glucosidase activity in a dose-dependent manner. The concentration required to reach $50 \%$ inhibition $\left(\mathrm{IC}_{50}\right)$ was approximately $3.0 \mu \mathrm{M}$ (Fig. 1A). Double-reciprocal plot of $\alpha$-glucosidase kinetics showed noncompetitive inhibition of $\alpha$-glucosidase activity by lignosulfonic acid (Fig. $1 B)$. The $K_{\mathrm{i}}$ value, which was determined using Dixon plot, was $10.6 \mu \mathrm{M}$. To determine whether the binding to $\alpha$-glucosidase was reversible, lignosulfonic acid was preincubated with the enzyme for $30 \mathrm{~min}$ at $25^{\circ} \mathrm{C}$ and then was fractionated by the Amicon Ultra Centrifugal Filter Device with a $10 \mathrm{~K}$ molecular weight exclusion limit. Lignosulfonic acid- $\alpha$-glucosidase complex and $\alpha$-glucosidase are concentrated on the filter and free lignosulfonic acid is removed as filtrate. Before filtration, lignosulfonic acid led to, approximately, $80 \%$ inhibition of $\alpha$-glucosidase activity. After filtration, however, the enzymatic activity of the concentrated solution recovered to approximately $80 \%$ of the initial value (Fig.
1C), indicating that the binding of lignosulfonic acid to $\alpha$-glucosidase was reversible. An increase in preincubation time with the enzyme, exacerbated the inhibitory effect of lignosulfonic acid (Fig. 1D).

Inhibition of 2-deoxyglucose uptake in Caco-2 cells by lignosulfonic acid

Next, we examined the effect of lignosulfonic acid on 2-deoxyglucose uptake in Caco-2 cells. Caco-2 cells have been widely used as an in vitro model of human intestinal absorption. Uptake of 2-deoxyglucose was inhibited significantly in the presence of lignosulfonic acid (Fig. 2A) with $80 \%$ inhibition observed at $62.5 \mu \mathrm{M}$ of lignosulfonic acid. At this concentration, lignosulfonic acid did not affect Caco-2 cell viability estimated by MTT assay (Fig. 2B).

Effect of lignosulfonic acid on diffusion of glucose

It has been suggested that viscous dietary fibers lower postprandial serum glucose concentration by retarding glucose diffusion in the small intestine (14). The effect of lignosulfonic acid on glucose diffusion was investigated (Fig. 3). The diffusion velocity of glucose was not affected in the presence of lignosulfonic acid at concen- 

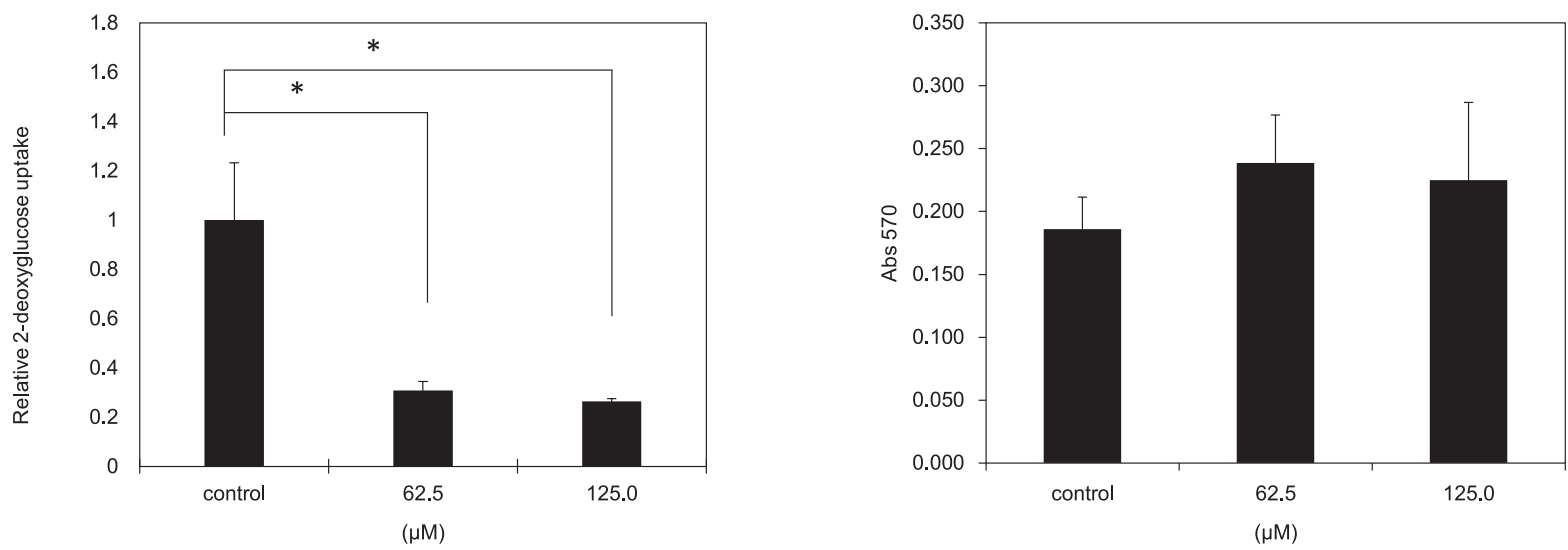

Fig. 2. Effect of lignosulfonic acid on 2-deoxyglucose uptake (A) and cell viability (B) in Caco-2 cells. (A) The amount of 2-deoxyglucose uptake was shown as relative 2-deoxyglucose uptake compared with that (47.6 pmol/well) in the absence of lignosulfonic acid. Data represents an average of the measurements taken from 6 wells out of a 24-well plate \pm SE. Statistical significance was determined by one-way ANOVA with Turkey's test: ${ }^{*} p<0.05$ relative to vehicle alone. (B) Lignosulfonic acid was added to Caco-2 cells at concentrations of $62.5 \mu \mathrm{M}$ or $125 \mu \mathrm{M}$. After $24 \mathrm{~h}$, cell viability was measured by MTT assay. Control shows cell culture in the absence of lignosulfonic acid.

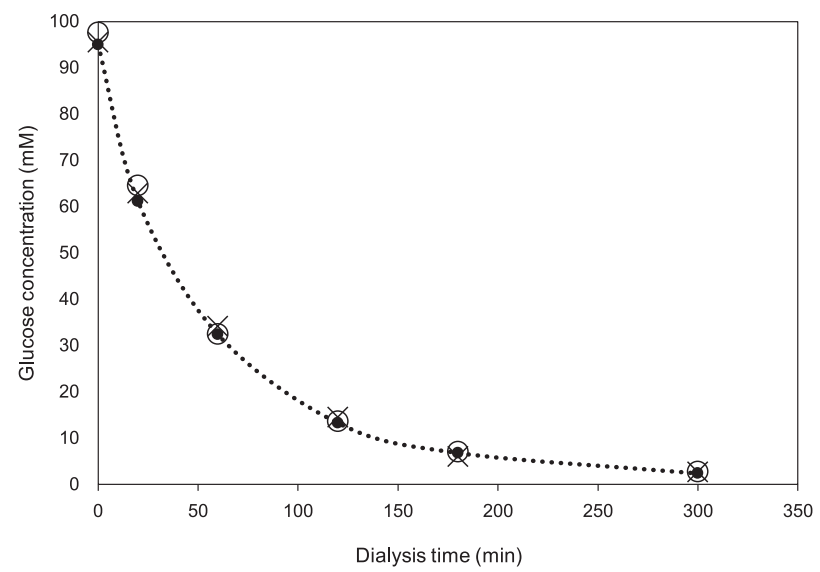

Fig. 3. Effect of lignosulfonic acid on glucose diffusion. Glucose diffusion was determined in the absence or presence of lignosulfonic acid at concentrations of $12.5 \mu \mathrm{M}(\bigcirc)$ and $125 \mu \mathrm{M}(\times)$. Glucose concentration in the dialysis tube was measured at the indicated time before and after the start of dialysis. Each value represents the average of triplicate samples.

trations of $12.5 \mu \mathrm{M}$ and $125 \mu \mathrm{M}$.

Effect of lignosulfonic acid on the blood glucose levels after an oral administration of glucose and sucrose

To estimate the in vivo effect of lignosulfonic acid, we investigated whether the compound could inhibit the rise in the blood glucose levels after sucrose or glucose loading in rats. As shown in Fig. 4A, following oral administration of sucrose $(1.5 \mathrm{~g} / \mathrm{kg})$, the blood glucose concentration increased from 45 to $120 \mathrm{mg} / \mathrm{dL}$ in $30 \mathrm{~min}$, and decreased thereafter. The rise in blood glucose level was significantly suppressed, and the area under the curve (AUC) decreased (Fig. 4B) when either $50 \mathrm{mg} / \mathrm{kg}$ or $100 \mathrm{mg} / \mathrm{kg}$ of lignosulfonic acid was given simultaneously with sucrose. Likewise, treatment with $50 \mathrm{mg} / \mathrm{kg}$ or $100 \mathrm{mg} / \mathrm{kg}$ of lignosulfonic acid delayed and suppressed the rise in blood glucose concentration following glucose loading (Fig. 4C and D). These results suggest that, by inhibiting $\alpha$-glucosidase activity and intestinal glucose uptake, lignosulfonic acid can suppress the rise of blood glucose levels in vivo.

Fecal sugar content in rats fed lignosulfonic acid

To further confirm the results described above, we investigated whether feeding lignosulfonic acid to the rats would cause an increase in fecal sugar content. Rats were fed either a control diet (control group) or a diet supplemented with 5\% lignosulfonic acid (lignosulfonic acid group) for 4 wk. Neither body weights nor weight of tissue-to-body weight ratios differed significantly between the lignosulfonic acid and control groups (data not shown). While ingestion of lignosulfonic acid did not affect fecal dry weight (Fig. 5A), fecal sugar content was increased by approximately $170 \%$ relative to the control (Fig. 5B). These results further support our findings of lignosulfonic acid's in vivo inhibitory effect on $\alpha$-glucosidase activity and intestinal glucose uptake.

\section{DISCUSSION}

In this study, we performed an $\alpha$-glucosidase inhibition assay using yeast $\alpha$-glucosidase, because yeast $\alpha$-glucosidase is readily available in a purified form and has been widely used for the screening of potent inhibitors with anti-diabetic activity. Although the inhibition effect is known to be different between yeast $\alpha$-glucosidase and mammalian small intestine $\alpha$-glucosidase (15), many substances have been reported to inhibit both $\alpha$-glucosidase $(16,17)$.

We showed that lignosulfonic acid inhibits $\alpha$-glucosidase activity. Similar inhibition was also produced by alkali lignin, which includes a thiol group instead 
(A)

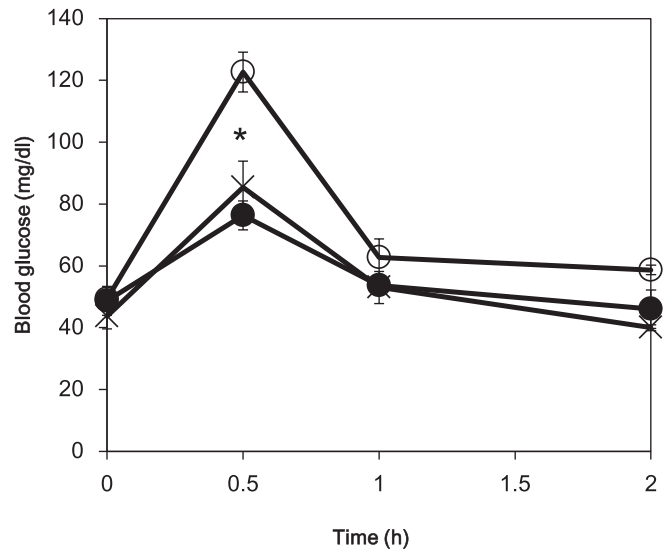

(C)

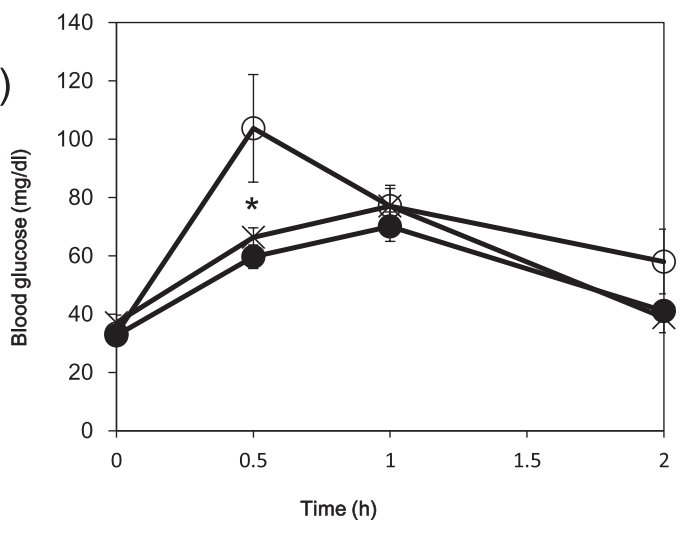

(B)

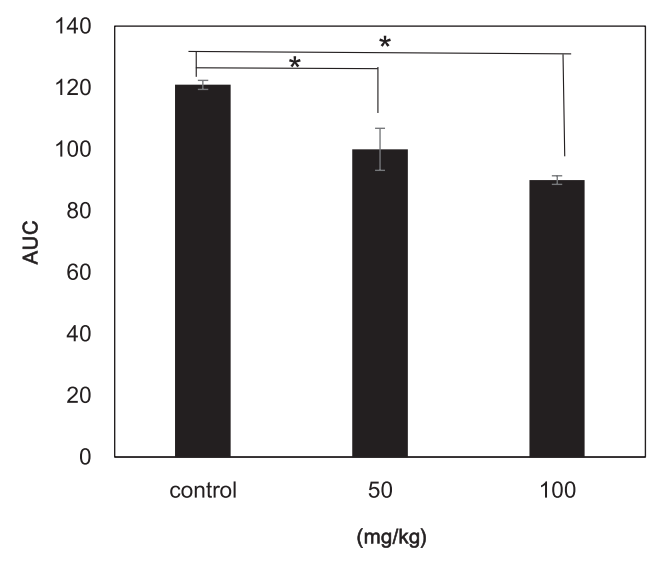

(D)

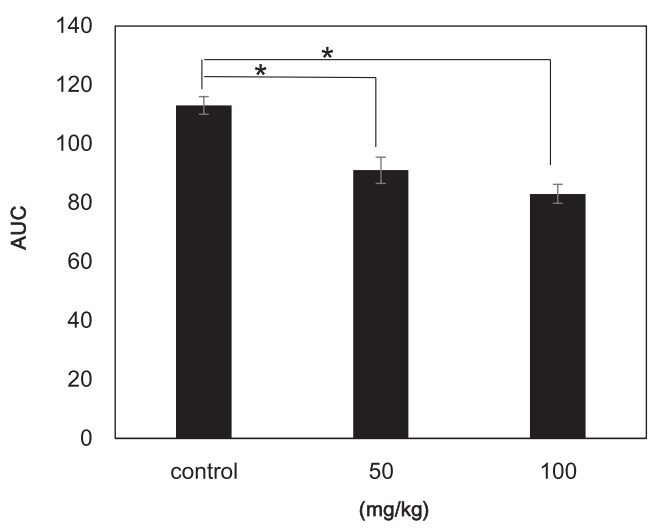

Fig. 4. Effect of lignosulfonic acid on blood glucose levels after oral administration of sucrose (A and B) or glucose (C and D). Rats ( $n=4$ per group) received glucose or sucrose with either $50 \mathrm{mg} / \mathrm{kg}(\times)$ or $100 \mathrm{mg} / \mathrm{kg}(\mathbf{O})$ of lignosulfonic acid. Control rats were given only sucrose or glucose $(\bigcirc)$. Blood glucose levels were measured at the indicated time intervals and AUC was calculated for both sucrose (B) and glucose (D) loading. Results are presented as mean \pm SE $(n=4)$. Statistical significance was determined by one-way ANOVA with Turkey's test: ${ }^{*} p<0.05$ relative to control rats.

(A)

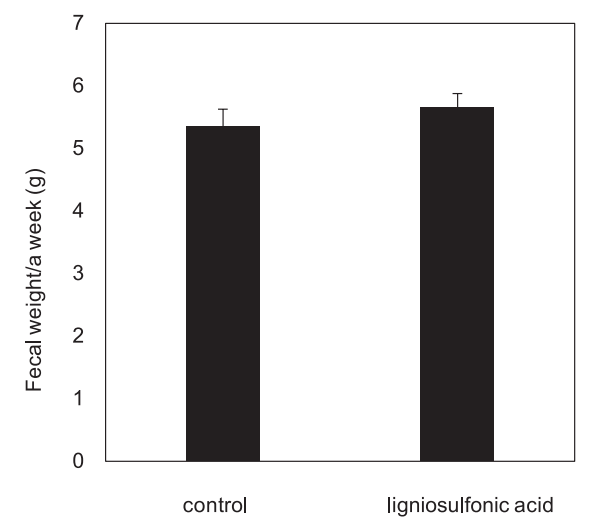

(B)

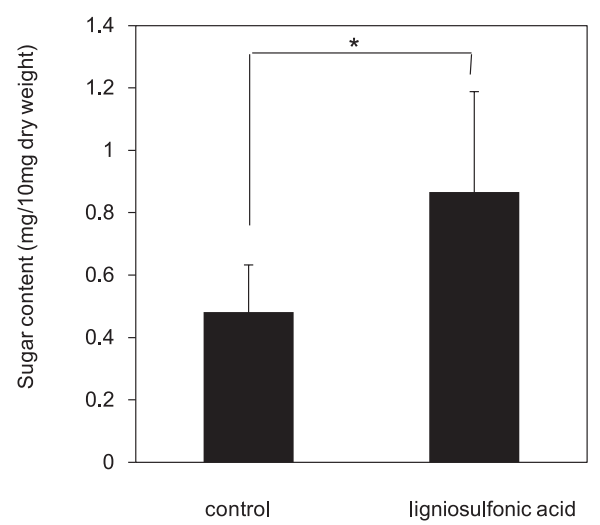

Fig. 5. Effect of lignosulfonic acid on fecal weight and sugar content. Fecal weight (A) and fecal sugar content (B) were measured as described in "Materials and Methods." Data shown represent the measurements taken from 5 animals per group \pm S.E. Statistical significance was evaluated by Student's $t$-test $\left({ }^{*} p<0.05\right)$.

of a sulfate group (data not shown), suggesting that the inhibition is not attributable to the sulfate or thiol group. Lignin is a complex phenolic polymer containing 4-hydroxyphenyl, 4-hydroxy-3-methoxyphenyl, and 4-hydroxy-3,5-dimethoxyphenyl groups. Interestingly, ferulic and $p$-coumaric acids, which contain 4-hydroxy3-methoxyphenyl and 4-hydroxyphenyl, respectively, have failed to inhibit $\alpha$-glucosidase activity $(18,19)$. Thus, the more complex structure of lignosulfonic acid might contribute to its inhibitory activity.

Lignosulfonic acid has been shown to be a reversible and non-competitive inhibitor of $\alpha$-glucosidase, indicating that it can bind both the enzyme and enzymesubstrate complex. The inhibitory effect of lignosulfonic 
acid on $\alpha$-glucosidase activity was enhanced by the preincubation of lignosulfonic acid with the enzyme, suggesting that the mechanism of inhibition might involve a slow binding of lignosulfonic acid to $\alpha$-glucosidase, similar to that reported in the case of genistein (12).

Lignins are the major components of dietary fiber. It has been reported that viscous dietary fiber has the ability to hamper the diffusion of glucose, thus postponing the absorption and digestion of carbohydrates and lowering the rise in blood glucose levels (14). However, lignosulfonic acid did not affect the diffusion velocity of glucose (Fig. 3).

In the intestine, glucose is absorbed by glucose transporters. Co-administration of glucose and lignosulfonic acid delayed and suppressed the increase in blood glucose concentration compared to administration of glucose only, suggesting that lignosulfonic acid could interfere with and delay the absorption of glucose into the small intestine by inhibiting glucose transport. This is supported by the in vitro data that lignosulfonic acid inhibited 2-deoxyglucose uptake in Caco-2 cells.

Ingestion of lignosulfonic acid did not affect fecal dry weight, but produced softer feces than for the control (data not shown). This may be due to the water-holding capacity of lignosulfonic acid as well as dietary fibers (20). Fecal sugar content in rats fed a diet supplemented with lignosulfonic acid was increased relative to the control. The increase does not seem to be affected by the water-holding capacity.

Our results show that lignosulfonic acid suppresses the rise in blood glucose levels through the inhibition of $\alpha$-glucosidase activity and intestinal glucose absorption. Lignins are non-toxic compounds present in commonly consumed vegetables, cereal brands and fruits. They might one day be used to treat diabetes. However, it remains uncertain whether insoluble lignins in food and lignosulfonic acid have similar functions. Therefore, in the future, it would be interesting to examine the effects of foods with high concentrations of lignins (e.g., cacao, burdock and certain cereals).

\section{REFERENCES}

1) Glennie DW. 1971. Reactions in sulfite pulping. In: Lignin: Occurrence, Formation. Structure and Reactions (Sarkanen KV, Ludwing CH, eds), p 597-637. Wiley, New York.

2) Xiao Z, Andreas G, Richard GV. 2006. Porous lignosulfonate membranes for direct methanol fuel cells. J Membrane Sci 276: 301-307.

3) Zhe W, Jingwen X, Jishi Z, Wenxia L. 2012. Concrete superplasticizer prepared from catalytic oxidation of lignosulfonate. Adv Mater Res 424: 1088-1092.

4) Kuschner K. 1928. Preparation of large amounts of vanillin from sulfite waste liquors. J Prakt Chem 118: $238-264$.
5) Eastwood MA, Hamilton D. 1968. Studies on the absorption of bile salts to non-absorbed components of diet. Biochem Biophys Acta 152: 165-173.

6) Barnard DL, Heaton KW. 1973. Bile acids and vitamin A absorption in man: the effects of two bile acid-binding agents, cholestyramine and lignin. Gut 14: 316-318.

7) Dizhbite T, Telysheva G, Jukjane V, Viesturs U. 2004. Characterization of the radical scavenging activity of lignins-natural antioxidants. Biores Technol 95: 309-317.

8) Pouteau C, Dole P, Cathala B, Averous L, Boquillon N. 2003. Antioxidant properties of lignin in polypropylene. Polym Degrad Stabil 81: 9-18.

9) Reddy BS, Maeura Y, Wayman M. 1983. Effects of dietary corn bran and autohydrolyzed lignin on 3,2-dimethyl4-aminobiphenyl-induced intestinal carcinogenesis in male F344 rats. J Natl Cancer Inst 71: 419-423.

10) Yamamoto Y, Shirono H, Kono K, Ohashi Y. 1997. Immunopotentiating activity of the water-soluble lignin rich fraction prepared from LEM-The extract of the solid culture medium of Lentinus encodes mycelia. Biosci Biotechnol Biochem 61: 1909-1912.

11) Qiu M, Wang Q, Yuan Z, Song H, Chen Z, Wu Z. 2012. Lignosulfonic acid exhibits broadly anti-HIV-1 activity potential as a microbicide candidate for the prevention of HIV-1 sexual transmission. PLoS One 7: 1-12.

12) Lee DS, Lee SH. 2001. Genistein, a soy isoflavone, is a potent $\alpha$-glucosidase inhibitor. FEBS Lett 501: 84-86.

13) Manthorpe M, Fagnani R, Skaper SD, Varon S. 1986. An automated colorimetric microassay for neuronotrophic factors. Brain Res 390: 191-198.

14) Ou S, Kwok KC, Li Y, Fu L. 2001. In vitro study of possible role of dietary fiber in lowering postprandial serum glucose. J Agric Food Chem 49: 1026-1029.

15) Oki T, Matsui T, Osajima Y. 1999. Inhibitory effect of $\alpha$-glucosidase inhibitors varies according to its origin. $J$ Agric Food Chem 47: 550-553.

16) Toobaei Z, Yousefi R, Panahi F, Shahidpour S, Nourisefat M, Doroodmand MM, Khalafi-Nezhad A. 2015. Synthesis of novel poly-hydroxy functionalized acridine derivatives as inhibitors of $\alpha$-glucosidase and $\alpha$-amylase. Carbohydr Res 411: 22-32.

17) Kim MJ, Lee SB, Lee HS, Lee SY, Baek JS, Kim D, Moon TW, Robyt JF, Park KH. 1999. Comparative study of the inhibition of $\alpha$-glucosidase, $\alpha$-amylase, and cyclomaltodextrin glucanosyltransferase by acarbose, isoacarbose, and acarviosine-glucose. Arch Biochem Biophys 371: $277-283$.

18) Nishioka T, Kawabata J, Niki R. 1997. Isolation and activity of $N$-p-coumaroyltyramine, an $\alpha$-glucosidase inhibitor in welsh onion (Allium fistulosum). Biosci Biotechnol Biochem 61: 1138-1141.

19) Niwa T, Doi U, Osawa T. 2003. Inhibitory activity of corn-derived bisamide compounds against alpha-glucosidase. J Agric Food Chem 51: 90-94.

20) McConnell AA, Eastwood MA, Mitchell WD. 1974. Physical characteristics of vegetable food stuffs that could influence bowel function. J Sci Food Agric 25: 1457-1464. 